\title{
Earth as Building Material - an overview of RILEM activities and recent Innovations in Geotechnics
}

\author{
Johan Vyncke ${ }^{1}$, Laura Kupers ${ }^{2}$ and Nicolas Denies ${ }^{3}$ \\ ${ }^{1}$ Belgian Building Research Institute, Research and Innovation Department, Limelette, Belgium \& President of RILEM \\ ${ }^{2}$ Belgian Building Research Institute, Laboratory of Concrete Technology, Limelette, Belgium \\ ${ }^{3}$ Belgian Building Research Institute, Geotechnical Division, Limelette, Belgium
}

\begin{abstract}
This paper presents an overview of the different earth building techniques, the latest innovations and the normative aspects. The oldest man made earth constructions known to exist date back to $10000 \mathrm{BC}$. Since then, earth has remained a popular building material throughout history. With time, different techniques evolved, starting from sundried adobe blocks to cob constructions, rammed earth walls and compressed earth bricks. Today these techniques are still being optimized and alternative binders, specifically adapted admixtures and surface treatments are being developed. Even though nearly one third of the world's population lives in an earth construction, few specific building standards and testing methods exist. Many of the tests used today are based on tests for concrete and thus do not take into account the complex nature of earth constructions, such as their sensitivity to water. RILEM, the union of Laboratories and Experts in Construction Materials, Systems and Structures, set up a new Technical Committee in 2016: TC TCE (Testing and Characterisation of Earth-based building materials and elements). This committee, consisting of an international group of experts on the topic, aim to define testing procedures for earth as a building construction material. To end with, this paper also gives a short introduction to "Deep soil mixing", an "earth" building technique dedicated to geotechnical engineering.
\end{abstract}

\section{Introduction}

The oldest manmade earth constructions known were found in Mesopotamia, and date from $10000 \mathrm{BC}$, they consist of stacked earth bricks. Remains of rammed earth foundations as old as $5000 \mathrm{BC}$ were found in Assyria. For these archaeological constructions, mixtures of locally excavated sand, gravel and clay were used [1, 2, $3]$.

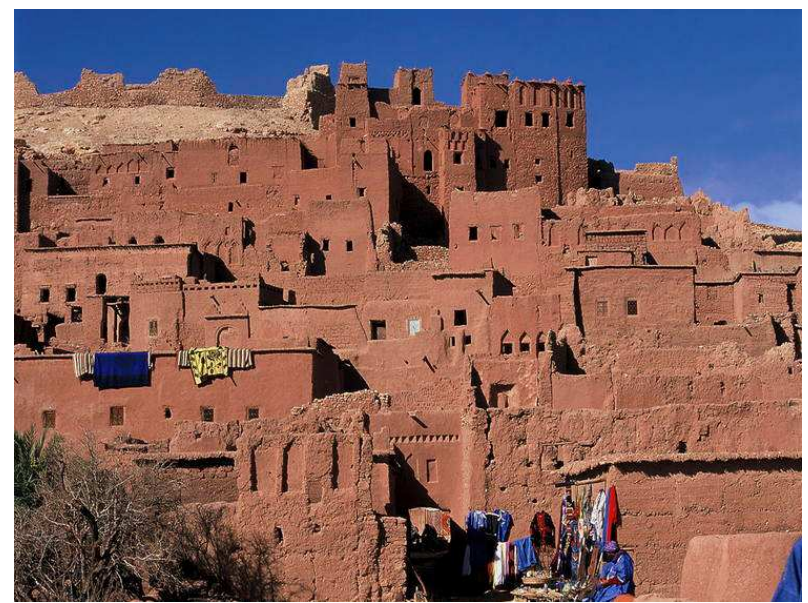

Fig. 1. Fortified village of Ait Ben-Haddou (Photo: uneco.org).
There are many historical monuments made of earth constructions all around the world. Just a few examples are the temple of Ramses II at Gourna, Egypt, the citadel of Bam in Iran, the core of the Sun Pyramid in Teotihuacan, Mexico, the Potala Palace in Tibet, the fortified village of Ait Ben-Haddou in Ouarzazate, Morocco (see Figure 1) etc. [1,2].

Today earth still remains an important building material. Nearly $30 \%$ of the world's population lives in buildings made of earth [1]. Figure 2 illustrates the worldwide application of earth building.

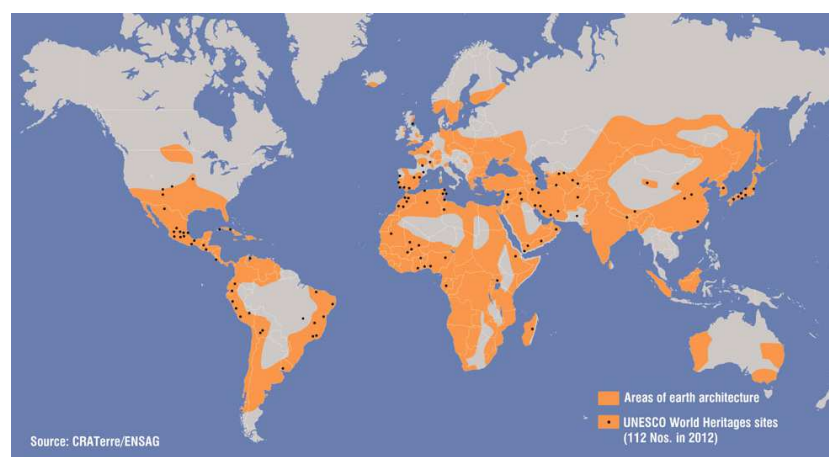

Fig. 2. World map illustrating the worldwide use of earth construction [4]. 
In developing countries even more than half of the population lives in earth construction. But also in the industrialized countries, building with earth is regaining some interest as it is regarded as an environmentally friendly option due to its low carbon footprint, low thermal conductivity and good hygroscopic features $[1,5$, $6]$.

For modern earth constructions often local soil is mixed with imported materials such as quarry dust, sand and gravel from quarries located at further distance to achieve a suitable mix design [7]. Also additives, such as slaked lime, cement or (synthetic) fibres, are added to the soil mixture in order to achieve higher compressive strength and better durability.

It has been proven that it would be impossible to fulfil the housing demand by the "classical" building materials such as bricks, concrete and steel [2] if earth would not be used. Earth is available in abundance, it is everywhere locally available and cheap [8]. However, some of the drawbacks are the loss of strength due to saturation, its sensitivity to erosion by rain impact and, more generally, its durability [9]. Nevertheless, this can largely be resolved by taking appropriate architectural measures such as large roof-overhangs, high footings and good drainage [10].

Not all soils are suitable for application as building material. Important parameters are the grain size distribution, the clay content, the mineralogical and chemical composition, the organic material content, etc. Depending on the building technique there are different requirements. The raw material must in many cases be prepared before being applied. Preparation usually consists of pulverisation, sieving, and/or drying [2, 8, 11, 12].

\section{The different earth building techniques}

\subsection{Rammed earth}

Rammed earth is a building technique in which a wet mixture of mud, sand and gravel is poured in a formwork and is compacted layer by layer $[1,2]$. Because of the layer approach, rammed earth constructions are characterized by a horizontally striped pattern. By using different coloured soils this effect can deliberately be emphasized as illustrated in Figure 3.

Originally, the ramming was manually performed but in the $20^{\text {th }}$ century, electric and pneumatic rams were developed [2]. Today the technique has evolved in such a way that the rammed earth constructions can specifically be designed to achieve high compressive strength and fulfil aesthetic requirements. For the execution, sophisticated materials and machinery, such as laminate plywood, aluminium form supports, conveyor belts, pneumatic air compressors, mixing machines and tractors, can be used [7].

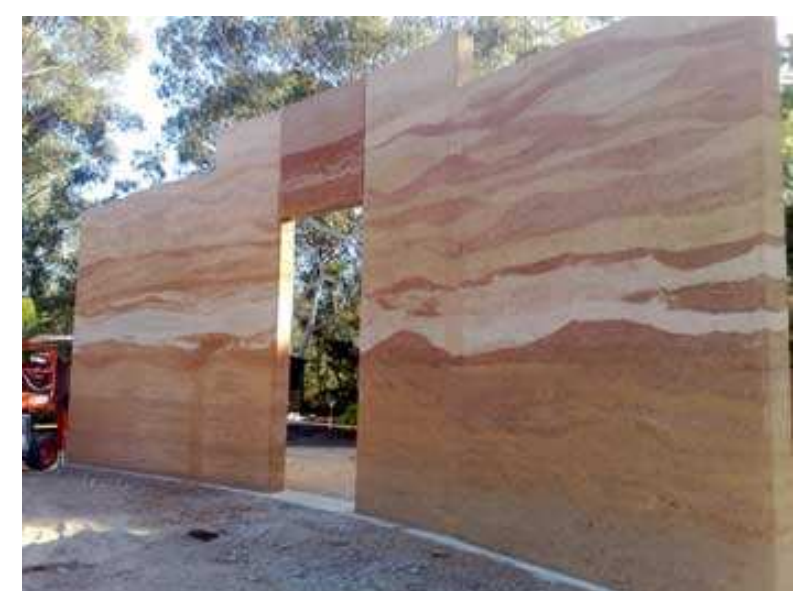

Fig. 3. Multi coloured rammed earth wall at Brisbane, Australia (Photo: rammedearthconstructions.com).

\subsection{Cob constructions}

The great Mosque Djenné, an UNESCO World Heritage Site, is probably the most famous cob construction. Cob is a building technique in which plastic (clayey) soil mixtures are formed in balls and freshly stacked upon each other, as illustrated in Figure 4. The soil mixture typically consists of soil and water and often straw and sand are added. This technique is used a lot in Africa, India and Saudi Arabia. In England and France, this technique was also used a lot in the past and it is now slowly regaining some interest [4].

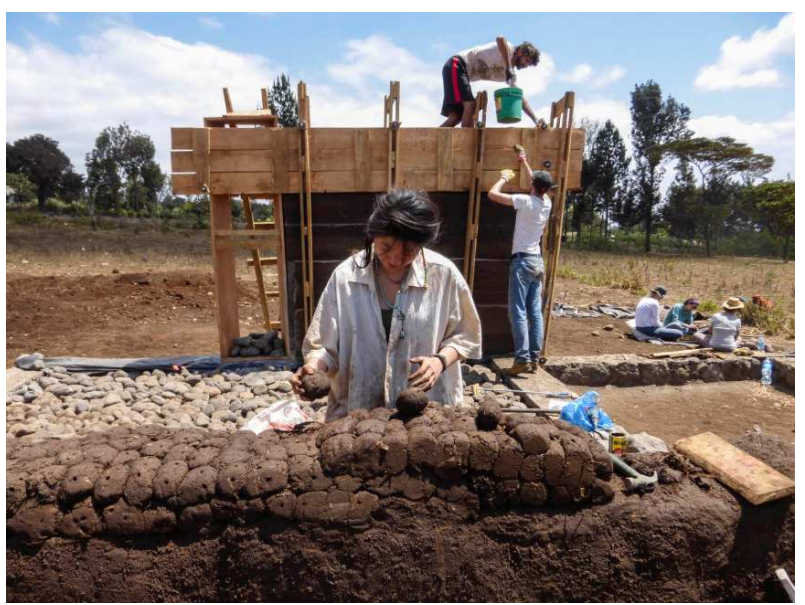

Fig. 4. Construction of a cob wall by stacking mud balls (Photo: tanzaniagoesmud.wordpress.com).

\subsection{Earth blocks}

Earth blocks can be divided in three groups, "adobe blocks", "cut blocks" and "compressed earth blocks", depending on the technique used to form the block.

\subsubsection{Adobe blocks}

Adobe blocks are sun dried bricks. A muddy soil mixture, often containing cut straw, is shaped into blocks by filling a formwork. After shaping the blocks are left to dry in the sun and harden $[2,12]$. 


\subsubsection{Cut blocks}

In regions where the soil itself is sufficient cohesive, blocks can be cut out directly out of the soil. This technique is referred to as "cut blocks" [12] and is illustrated in Figure 5. Laterite, a soil formed by intense weathering in tropical climates and characterized by a high iron and aluminium concentration giving it its characteristic red colour, is well suited for this form of application. This technique is for example used in India [13] (see Figure 5). Once cut in blocks and exposed to air, the relatively soft soil hardens (indurates) due to dehydration of the iron and aluminium oxides and arrangements of components.

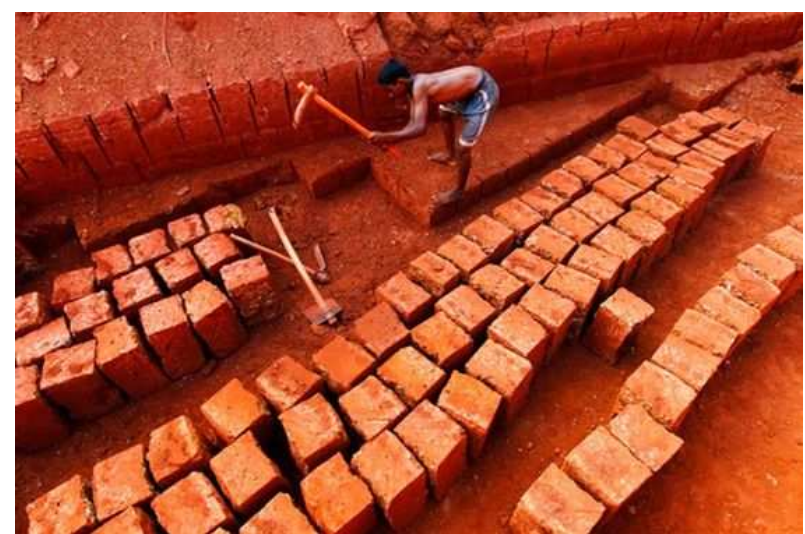

Fig. 5. A laterite block mine in Ratnagiri, India. The blocks are cut out of the soil. (Photo: news.uk.msn.com).

\subsubsection{Compressed earth blocks}

In the $18^{\text {th }}$ century, the technique to produce "compressed earth blocks" (CEB's) by means of a manual press became popular in Europe. This technique made it possible to work with lower water contents in the soil mixtures than for the adobe blocks and the blocks can be stacked immediately after production. In order to improve the strength of the bricks, cement or lime was added to the soil mixture [2]. Nowadays large industrial presses for producing compressed earth blocks exist, but none the less the manual press is still very popular. Figure 6 illustrates two technicians operating a manual press in the laboratory facilities of the Belgian Building Research Institute (BBRI) where tests on Laterite blocks have been performed for a potential development project in Africa.

The shape of the compressed earth block is determined by the shape of the mold. Most presses can be equipped with a large variety of mold shapes going from different sized rectangular blocks to blocks with rounded angels, blocks with holes (interlocking), sinus-shaped self-blocking blocks to blocks with recess for cables, etc.

\section{Mix design and production of CEB's}

Just as for concrete constructions, the mix design for earth blocks is important with regard to the final properties (workability, strength, shrinkage...). However, earth constructions have the additional disadvantage that the characteristics of the used earth often vary significantly. For a minimal quality control, the used earth

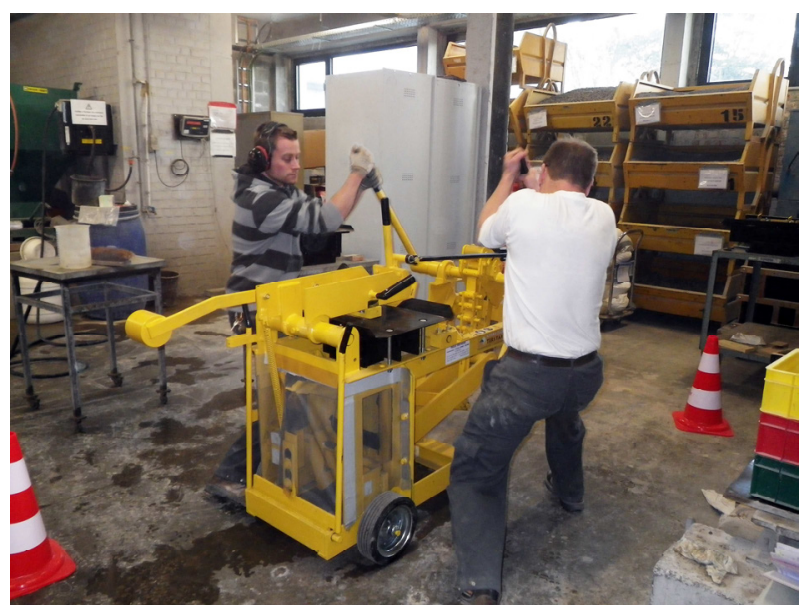

Fig. 6. Manual press for the production of compressed earth blocks (Source: BBRI).

should therefore be submitted to standard testing (Atterberg limits, methylene blue content, organic material content, etc.) during the production process so that the mix design can be adapted if necessary.

For CEB's, most often a mixture of earth, cement and water is used. The cement/earth and water/cement ratios found in the literature differ greatly - ranging from respectively 0.02 to 0.50 , and from 0.5 to $3.9[14,15,16$, 17, 18, 19]. These differences can amongst others be attributed to the variation of the used earth and the intended application and desired strength of the blocks.

The cement in the mixture stabilizes the earth by creating a network of hydrated calcium silicate (CSH). A higher cement content results in a denser CSH network thus increasing the compressive strength of the earth block. Sufficient water is needed in the mixture to hydrate the cement and to allow an optimum compression, but a too high water/cement ratio decreases the compressive strength and leads to an increased risk of shrinkage cracks. Sometimes (river) sand is added to improve the particle size distribution or to reduce the percentage of (swelling) clays of the soils $[11,13,18,19]$.

In addition to the mix design, the production process is also important. Experiments show that the degree of compaction and the after-treatment conditions have an important effect on the final compressive strength of the laterite block $[18,20]$. After production, the blocks should be able to cure in humid conditions to allow maximum strength development. Tests at the BBRI showed that the difference between a "good cure" $\left(30^{\circ} \mathrm{C},>90 \%\right.$ R.H. $)$ and a "bad cure" $\left(30^{\circ} \mathrm{C},<60 \%\right.$ R.H. $)$ can amount to a loss of strength of more than $35 \%$.

\section{Research and innovation regarding earth constructions}

In order to improve the strength and durability of earth constructions, different universities and research institutes all around the world are engaged with scientific research in order to develop specific admixtures and surface treatments. Also the use of alternatives, such as ecofriendly binders, are investigated. In the present paragraph, different innovations are listed. 


\subsection{Alternative binders}

The most common stabilizers for earth constructions are lime and cement. Stabilizing CEBs with lime is possible if the earth used for the mix has a high clay content. If the earth consists dominantly of quartz (sandy soil), a stabilization with cement is recommended [2, 8 , $11,12]$

Recently, more and more researches concerning alternative binders are performed. A proposed alternative is, for example, the use of alkaline activation. Alkaline activated materials (AAM's), also called "geopolymers", are considered as more environmentally friendly than cement bonded materials due to substantial reduction in $\mathrm{CO}_{2}$ emissions $[21,22]$. If the earth contains an important clay fraction, the clay can act as a binder. Ternary diagrams, indicating if a resource is a potentially interesting material for alkaline activation, can be found in the scientific literature (see, for example, Figures 7 and 8).

The use of laterite as a potential AAM was tested by Maskell et al [23] and Marques et al [24]. In both cases, the activator $\mathrm{NaOH}$ was used. The studies indicated that for an optimal result, a hot curing of the CEBs (at least $55^{\circ} \mathrm{C}$ ) is required. Alkali activated laterite also requires a longer time to obtain its maximum strength than the cement-bonded reference blocks [24].

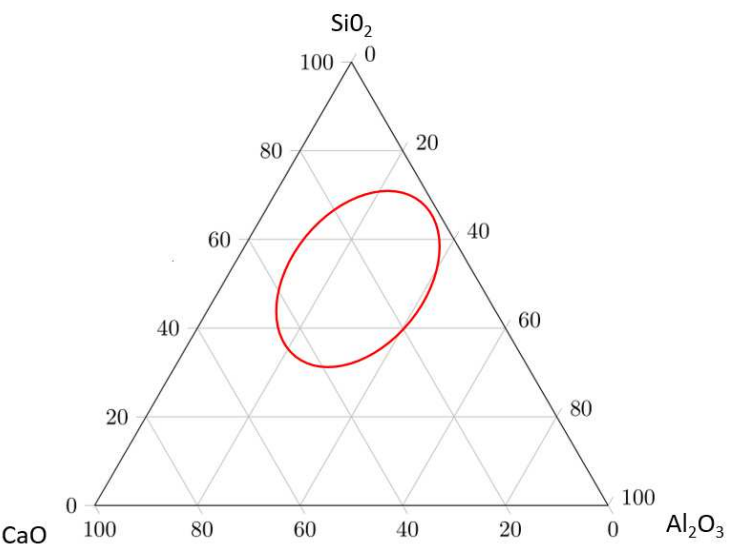

Fig. 7. Ternary Si-Ca-Al diagram showing the ideal chemical composition of potential AAM's [based on 25]

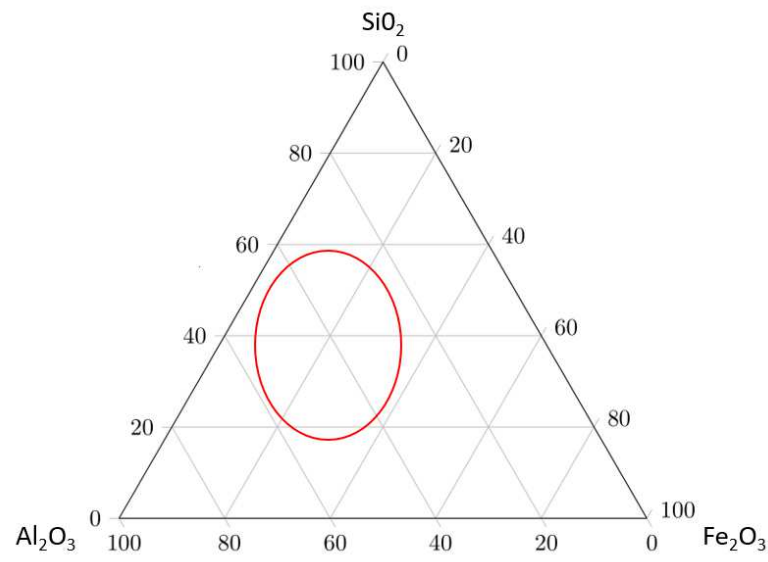

Fig. 8. Ternary Si-Al-Fe diagram showing the ideal chemical composition of potential AAM's [based on 26].

\subsection{Admixtures}

Specially adapted admixtures can improve the quality of earth constructions by making them less vulnerable to water penetration. For example, adding a low dosage hydrophobic silicone-based admixture could minimise the water absorption without affecting the vapour permeability [9].

\subsection{Surface treatments}

A surface treatment can significantly improve the surface quality of an earth construction. Many different surface treatments exist including water-repellent treatments, which make the constructions less vulnerable to water penetration, as well as dust suppressant sealing, renders and coatings etc.

The development of nano-acrylic emulsions, similar to the technology used for paint primers, will allow better dust binding without the negative impact on the vapour permeability as it is now the case with the traditional acrylic or latex emulsions. Also still in research phase are fluorinated silicones or fluorinated acrylic polymers sealers for areas that require repeated cleaning such as the kitchen, bathroom or public spaces [9].

\section{Standards and testing procedures}

Generally, building with earth has not been considered as an "engineered construction technique" in the past and thus building standards were considered unnecessary. However, due to the (re)increasing interest in earth constructions, building standards specifically dedicated to earth constructions have been drawn up the last years. In 2012, thirty-three different standards existed from 18 different countries (Australia, Brazil, Colombia, France, Germany, India, Kenya, Kyrgyzstan, New Zealand, Nigeria, Peru, Spain, Sri Lanka, Switzerland, Tunisia, Turkey, USA and Zimbabwe) which were published by regional, national or local standard bodies.

Nevertheless, there is still no common and internationally accepted terminology for earth building constructions. Moreover, the technical information in the different standards varies widely and no uniform and internationally accepted laboratory tests exist for the moment.

Most of the test procedures described in the existing standards for earth constructions were originally developed for the testing soils or concrete. Thus, they are not always suitable for earthen building materials [27].

\section{RILEM activities}

RILEM is the Union of Laboratories and Experts in Construction Materials, Systems and Structures. It especially endeavours to advance scientific knowledge related to the use of concrete, masonry, wood, asphalt, and other construction materials and to encourage the worldwide transfer and application of this knowledge. The essential work of RILEM is done in Technical Comities (TC's) which are set up in a Bottom-Up 
approach, i.e. it are the corporate members and individual members who bring forward the proposals for action. Those are then evaluated on their merits by a technical advisory committee who also provides in monitoring of the progress of the TC's.

Work on earth as building material was initiated in RILEM back in 1996 in the TC 164-EBM where the focus was developing a test method to determine the mechanical strength for compressed earth samples by means of compression and tensile traction tests [28, 29]. Also tests to characterise the durability of the cement-stabilized compressed earth blocks which are subjected to wettingdrying (artificial aging) were performed [30].

Due to the lack of uniform and internationally accepted tests for earth building materials, the TC TCE "Testing and characterisation of earth-based building materials and elements" was initiated in 2016. Their goal is to define testing procedures for stabilized and unstabilized earth as a building construction material in adobe blocks, cob and rammed earth. The required characteristics of the used earth mixture as well as the evaluation of the performances (sustainability, strength, seismic resistance, thermal, moisture buffering...) of the earth building material are treated. A minimal number of laboratory tests allowing an accurate assessment of the mechanical, thermal and hygroscopic performances of the material will be defined. In order to evaluate the repeatability and the robustness of the tests, round robin tests are performed. The experimental developments should serve as a basis for the establishment of international or European standards on earth material testing procedures. The technical committee consists of more than 30 active members from all over the world and all specialized in earth constructions [31].

\section{Deep soil mixing}

Another, innovative and relatively new application of building with earth is the deep soil mixing. In contrast with the techniques discussed in the previous paragraphs (rammed earth, cob, earth blocks), this technique does not require excavation of the earth. In the deep soil mixing process, the earth is mechanically mixed in place and in depth by an auger or a cutter machine (see Figure 9) while a binder, often based on cement, is injected. Depending on the application, 100 to $600 \mathrm{~kg}$ of cement per $\mathrm{m}^{3}$ of mix is added. After hardening of the earth-cement mixture, further referred as the "soil mix material", different ground improvement patterns can be obtained into the ground: cylindrical columns, rectangular panels, continuous barriers or global mass stabilization.

As reported in Denies and Huybrechts (2015) [32], since several decades, the deep mixing method is known as a ground improvement technique. The deep soil mixing is in this case used for the global stabilization of soft cohesive soils such as silt, clay and peat in order to obtain sufficient bearing capacity (e.g. for the foundation of a structure) or to increase the general stability of the soil (e.g. for the reinforcement of existing dikes or land levees). In this context, 100 to $300 \mathrm{~kg}$ of cement per cubic meter of mix are generally used in the design mix.
If originally, the deep mixing method was developed for ground improvement applications, it is currently more and more dedicated to various structural and environmental applications such as alternative to classical foundation solutions, earth-water retaining walls, cut-off walls, slope stabilization, in-situ remediation, liquefaction mitigation, land reclamations...

In Belgium, the soil mixing is mainly used for the construction of earth-water retaining walls within the framework of excavation works. In this particular application, cylindrical soil mix columns or rectangular panels are formed in the ground as illustrated in Figure 10. In order to build soil mix walls for the realization of an excavation, the cylindrical soil-cement columns or the rectangular soil mix panels are placed next to each other, in a secant way such as illustrated in Fig. 10. By overlapping the different soil mix elements, a continuous soil mix wall is built. The soil mix wall is then horizontally stabilized by shoring or anchoring. During execution, steel beams are installed into the fresh soil mix material to resist the shear forces and bending moments due to the earth-water pressure applying on the retaining wall. The role of the soil mix material is to transmit the stresses due to this earth-water pressure to the steel beams by way of an arching effect developing in the soil mix material due to the difference of stiffness between the steel and the soil mix material.

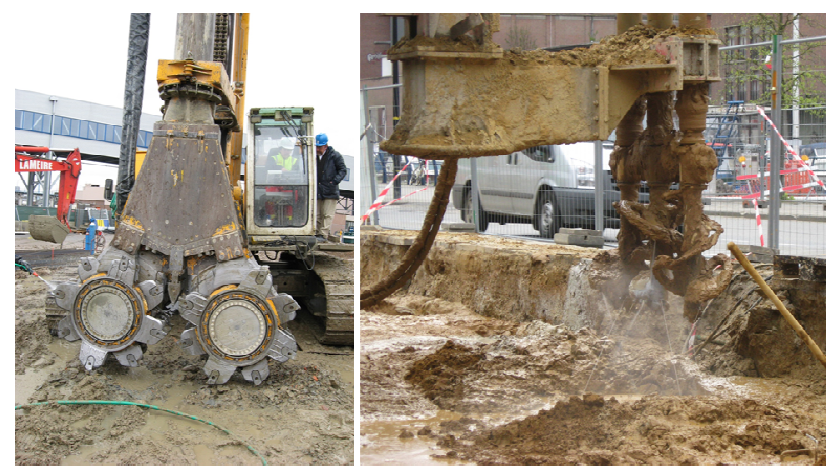

Fig. 9. Typical deep mixing equipment in action on Belgian construction sites: Cutter Soil Mix (CSM) system of Bauer (left) and triple shaft configuration TSM system of Smet F\&C (right).

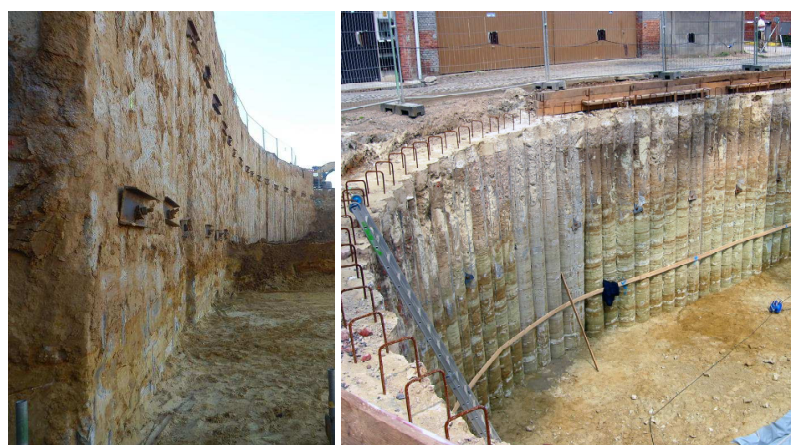

Fig. 10. Soil mix retaining walls within the framework of excavation works in Belgium: soil mix walls built with CSMpanels (left) and with the C-mix shaft system of CVRnv (right).

The success of this new application is based on the recent advances in the deep mixing equipment coupled with the development of binders allowing to reach typical unconfined compressive strength of 1 to $12 \mathrm{MPa}$ for the 
soil mix material. In Belgium, 200 to $450 \mathrm{~kg}$ (sometimes more) of cement per cubic meter of mix are typically used for the construction of soil mix retaining walls.

The soil-mix walls can be used as temporary or permanent geostructural elements and can fulfil different functions (earth-water retaining, bearing and cut-off).

This last decade, the Belgian Building Research Institute (BBRI) performed numerous tests on in-situ soil mix material for the purpose of characterizing its following properties: density, porosity, permeability, unconfined compressive strength (UCS), tensile strength, modulus of elasticity, ultrasonic pulse velocity and adherence between soil mix material and steel reinforcement [33]. Moreover, real-scale soil mix panels and columns were tested in order to obtain the real-scale UCS, the bending stiffness and the bending resistance of soil mix elements. Soil mix panels and columns previously executed on site were excavated after a few days of hardening and transported to the laboratory facilities of the BBRI to be tested [34]. On the basis of these results, the BBRI developed a design methodology, in line with the structural Eurocodes, for soil mix retaining walls. This methodology is described in detail in the BBRI/SBRCURnet soil mix handbook [35]. This handbook also contains information on the hydromechanical characteristics of the soil mix material.

Notwithstanding, more research is still required concerning questions such as:

- the influence of the deep mixing equipment on the final product,

- the minimal mixing energy to obtain a homogeneous soil-mix material,

- the durability of the soil mix material,

- the use of reinforcement cage in place of steel beams...

\section{EVALUATION}

Earth is regaining interest as a building material, not only in developing countries, where due to its abundance and low cost it is a logic and interesting building material for constructing superstructures, but also in modern societies where for reasons of sustainability and limiting transport it has an important advantage opposed to the conventional building materials. In this sense, a relatively new application of building with earth is the deep soil mixing process used within the framework of geotechnical projects. An advantage of this method in comparison with typical concrete solution is its independence from concrete supply on the field. Contrarily to concrete retaining walls, the execution of soil mix walls does not suffer from delayed supply (e.g. due to traffic jams) of the fresh concrete.

With regard to this regaining interest for earth constructions, there is clearly a need for the further development of specific testing techniques to allow further engineering development of earth applications as well as the development of quality standards. RILEM could surely play an important and pioneering role in this context.

\section{References}

1. C.S. Costa, F. Rocha \& A.L. Velosa. Sustainability in earthen heritage conservation. Sustainable use of Traditional Geomaterials in Construction Practice, 416 p 91-100 (2016)

2. G. Minke. Building with earth, Design and Technology of a Sustainable Architecture. Birkhäuser (2006)

3. P. Jaquin. History of earth building techniques. Modern Earth Buildings p 307-322 (2012)

4. Auroville Earth Institute, Unesco chair earthen architecture. Building with Earth - Technique overview. www.earth-auroville.com (accessed 2017 feb 17)

5. E.C. Hoff. Appraisal of the Sustainability of Compressed Stabilized Earthen Masonry. Dissertation Architectural Engineering, University of Nebraska - Lincoln (2016)

6. M.R. Hall, S. Cassey. Hygrothermal behavior and occupant comfort in modern earth buildings. Modern Earth Buildings p 17-40 (2012)

7. D. Easton, T. Easton. Modern rammed earth construction techniques. Modern Earth Buildings p 364-384 (2012)

8. E.A. Adam, A.R.A. Agib. Compressed Stabilised Earth Block Manufacture in Sudan. UNESCO 2001

9. R. Kebao, D. Kagi. Integral admixtures and surface treatments for modern earth buildings. Modern Earth Buildings p 256-281 (2012)

10. H. Guillaud, T. Joffroy, P. Odul, CRATerreEAG. Compressed earth blocks - Volume II. Manual of design and construction (1995)

11. V. Rigassi, CRATerre-EAG. Compressed earth blocks - Volume I. Manual of production (1995)

12. S. Boubekeur, H. Houben. Blocs de terre comprimée - normes. Guides pratiques Serie Technologies $\mathbf{N}^{\circ} 11$ (1996)

13. A.K. Kasthurba, M. Santhanam, M.S. Mathews. Investigation of laterite stones for building purpose from Malabar region, Kerala state, SW India - Part 1: Field studies and profile characterisation. Construction and Building Materials 21 p 73-82 (2007)

14. G. Otoko. The use of laterites for production of soil-cement blocks. International Journal of Engineering and Technology Research Vol. 2 $\mathbf{n}^{\circ} 4$ p 1-11 (2014)

15. F. Falade. The significance of source of laterite on strength of cement-stabilized lateritic blocks. Housing Science Vol 15 p 1241-131 (1991).

16. F. Lasisi, E. Ajayi, J. Osunade. Technical notes : Strength characteristics of lateritecement mortars. The International Journal of Cement Composites and Lightweigth Concrete Vol 6, n 3 p 201-203 (1984) 
17. K. Solomon-Ayeh. Studies of strengths of stabilized laterite blocks and rendering mortars. Building Research and Information Vol 22 n $^{\circ} 3$ p 159-166(1994)

18. I. Agbede, M. Joel. Use of Cement-Sand Admixtures in Laterite Brick Production for Low Cost Housing. Leonardo electronic journal of practices and technologies $\mathbf{1 2} \mathrm{p}$ 163-174 (2008)

19. G. Otoko, P. Pedro. Cement stabilization of laterite and chikoko soils using waste rubber fibre. International journal of engineering sciences \& research technology 3 p 130-136 (2014)

20. J. Ayangade, O. Alake, A. Wahab. The effects of different curing methods on the compressive strength of terracrete. Civil engineering dimension Vol. 11 p 41-45 (2009)

21. M. Estrada. A case study of cob earth based building technique in Matagalpa, Nicaragua LCA perspective and rate of adoption. Master Thesis Ecotechnology and Sustainable Development Mid Sweden University (2013).

22. E. Hoff. Appraisal of the Sustainability of Compressed Stabilized Earthen Masonry. Dissertation and Student Research Architectural Engineering University of Nebraska-Lincoln (2016)

23. D. Maskell, A. Heath, P. Walker. Geopolymer stabilisation of unfired earth masonry units. Key Engineering Materials, 600 p 175-185 (2014)

24. S. Marques, M. Carvalho, S. Torres, N. Perazzo, K. Gomes, K. Ghavami. Mechanical properties and durability of geopolymer stabilizated earth blocks (2009)

25. A. Buchwald, K. Dombrowski, M. Weil. The influence of calcium content on the performance of geoplymeric binder especially the resistance against acids. Proceedings of the World Congress Geopolymer 2005 p 35-39 (2005)

26. S. Kumar, R. Kumar. Synergising red (mud) and grey (ash) for greener geopolymers. Bauxite residue valorisation and best practices, Conference paper (2015)

27. H. Schroeder. Modern earth builiding codes, standards and normative development. Modern Earth Buildings p 72-109 (2012)

28. A. Hakimi, N. Yamani, H. Ouissi. Résultats d'essais de résistance mécanique sur échantillon de terre comprimée. Materials and Structures Vol 29 p 600-608 (1996)

29. M. Olivier, A. Mesbah, Z. El Gharbi, J. Morel. Mode opératoire pour la realisation d'essais de résistance sur blocs de terre comprimée. Materials and Structures Vol 30 p 515-517 (1997)

30. A. Hakami, H. Ouissi, M. El Kortbi, N. Yamani. Un test d'humification-séchage pour les blocs de terre comprimée et stabilisée au ciment. Materials and Structures Vol 31 p 20-26 (1998)

31. RILEM, International union of laboratories and experts in construction materials, systems and structures - Committees. www.rilem.org (accessed 2017 feb 20)

32 N. Denies and N. Huybrechts. Deep Mixing Method Equipment and field of applications. Book chapter 11 in Ground Improvement case histories, Elsevier (2015)

33. N. Denies, N. Huybrechts, F. De Cock, B. Lameire, A. Vervoort, G. Van Lysebetten, J. Maertens. Soil Mix Walls as retaining structures mechanical characterization. International symposium of ISSMGE - TC211 Vol. 3 p 99-115 (2012).

34. N. Denies, N. Huybrechts, F. De Cock, B. Lemaire, J. Maertens, A. Vervoort. Large-scale bending tests on soil mix elements. International Foundations Congress and Equipment Expo 2015, San Antonio (Texas, USA) p 2394-2409 (2015)

35. BBRI/SBRCURnet. Handboek soilmix-wanden. SBRCURnet/BBRI publication (2016) 